\title{
Changes in tumour vessel density upon treatment with anti-angiogenic agents: relationship with response and resistance to therapy
}

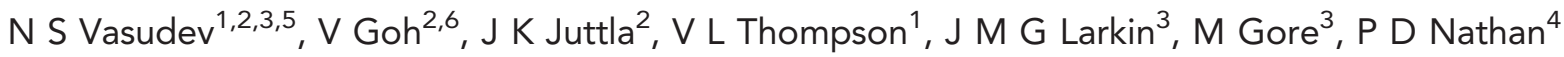 \\ and A R Reynolds*,1 \\ ${ }^{1}$ Tumour Biology Team, Breakthrough Breast Cancer Research Centre, The Institute of Cancer Research, London SW3 6JB, UK; \\ ${ }^{2}$ Paul Strickland Scanner Centre, Mount Vernon Hospital, Northwood HA6 2RN, UK; ${ }^{3}$ Royal Marsden Hospital, London SW3 6JJ, \\ UK and ${ }^{4}$ Department of Medical Oncology, Mount Vernon Cancer Centre, Northwood, HA6 2RN, UK
}

Background: We examine how changes in a surrogate marker of tumour vessel density correlate with response and resistance to anti-angiogenic therapy.

Methods: In metastatic renal cancer patients treated with anti-angiogenic tyrosine kinase inhibitors, arterial phase contrast-enhanced computed tomography was used to simultaneously measure changes in: (a) tumour size, and (b) tumour enhancement (a surrogate marker of tumour vessel density) within individual lesions.

Results: No correlation between baseline tumour enhancement and lesion shrinkage was observed, but a reduction in tumour enhancement on treatment was strongly correlated with reduction in lesion size $(r=0.654, P<0.0001)$. However, close examination of individual metastases revealed different types of response: (1) good vascular response with significant tumour shrinkage, (2) good vascular response with stabilisation of disease, (3) poor vascular response with stabilisation of disease and (4) poor vascular response with progression. Moreover, contrasting responses between different lesions within the same patient were observed. We also assessed rebound vascularisation in tumours that acquired resistance to treatment. The amplitude of rebound vascularisation was greater in lesions that had a better initial response to therapy $(P=0.008)$.

Interpretation: Changes in a surrogate marker of tumour vessel density correlate with response and resistance to anti-angiogenic therapy. The data provide insight into the mechanisms that underlie response and resistance to this class of agent.

The inhibition of vascular endothelial growth factor (VEGF) signalling can suppress tumour growth by suppressing tumour angiogenesis. Agents designed to target this pathway include the VEGF-A-neutralising antibody, bevacizumab, and a range of antiangiogenic receptor tyrosine kinase inhibitors (TKIs), including sunitinib, pazopanib, cediranib and regorafenib. Vascular endothelial growth factor pathway-targeted agents have been tested in numerous malignancies and have been approved in several indications, including metastatic breast, colorectal, lung, ovarian, and renal cancer; hepatocellular carcinoma; glioblastoma; and neuroendocrine tumours (Jayson et al, 2012; Sennino and McDonald, 2012). However, individual responses are variable, with some patients demonstrating resistance

${ }^{*}$ Correspondence: Dr AR Reynolds; E-mail: andrew.reynolds@icr.ac.uk

${ }^{5}$ Current address: Cancer Research UK Centre, Leeds Institute of Cancer Studies and Pathology, St James's University Hospital, Beckett Street, Leeds LS9 7TF, UK.

${ }^{6}$ Current address: Division of Imaging Sciences and Biomedical Engineering, King's College London, London SE1 7EH, UK.

Received 24 January 2013; revised 30 June 2013; accepted 4 July 2013; published online 6 August 2013

(C) 2013 Cancer Research UK. All rights reserved 0007 - 0920/13 
from the outset (intrinsic resistance) and others going on to develop resistance following a brief period of disease control (acquired resistance). Unfortunately, our understanding of what determines response and resistance to these agents is limited, and the answers to many fundamental questions are still unresolved. For example, what mechanisms underlie intrinsic and acquired resistance to these agents? Can response and resistance be predicted? How do we overcome resistance in order to improve the efficacy of this therapeutic approach? (Bergers and Hanahan, 2008; Ebos et al, 2009; Rini and Atkins, 2009; Ebos and Kerbel, 2011; Bottsford-Miller et al, 2012; Jayson et al, 2012; Sennino and McDonald, 2012).

In patients with metastatic renal cell carcinoma (mRCC), the administration of sunitinib or pazopanib as a single-agent therapy has been shown to extend progression-free and overall survival, and this form of therapy is now the standard of care for mRCC (Motzer et al, 2007, 2009; Sternberg et al, 2010). Nevertheless, $\sim 20 \%$ of mRCC patients demonstrate intrinsic resistance and derive no benefit. Moreover, although the majority of patients do achieve a period of disease control with these drugs, resistance is invariably acquired, typically within months of starting the treatment (Motzer et al, 2007, 2009; Sternberg et al, 2010; Busch et al, 2011; Heng et al, 2012). The current standard practice to treat with single-agent TKIs in this setting, combined with the manifestation of both intrinsic and acquired resistance, makes $\mathrm{mRCC}$ an important setting in which to explore the mechanisms that underlie response and resistance to anti-angiogenic therapy in patients.

Preclinical models show that, as well as blocking the formation of new tumour vessels, TKIs can induce the regression of newly formed immature vessels (Mancuso et al, 2006; Welti et al, 2011). Studies on tissue derived from renal cancer patients provide histological evidence that treatment of renal cancer with TKIs can induce a reduction in tumour vessel density (Griffioen et al, 2012; Powles et al, 2013). Therefore, TKIs can suppress the tumour vascularisation process, and this constitutes an important mechanism of action for these drugs. Although histological studies are informative, non-invasive longitudinal measurements of vascular parameters in tumours treated with anti-angiogenic agents are also desirable. For example, the amplitude of enhancement measured using arterial phase contrast-enhanced computed tomography (CECT) can be utilised as a surrogate measure of tumour vessel density in renal cancer. In support of this, correlative radiological-pathological studies show that the amplitude of the enhancement directly correlates with the tumour vessel density in renal cancer (Jinzaki et al, 2000; Wang et al, 2006). Moreover, when the measured enhancement is normalised to the enhancement of the aorta, inherent variations in phase, delivery and distribution of contrast between scans can be removed, thereby facilitating the direct quantitative comparison of enhancement (and of tumour vessel density, indirectly) in different lesions and in the same lesion at several different time points. Furthermore, changes in tumour vascular parameters measured using advanced imaging techniques have prognostic significance for mRCC patients treated with TKIs (O’Connor and Jayson, 2012).

In the current study, we have performed a retrospective analysis of arterial phase CECT scans obtained from 56 lesions in 23 mRCC patients treated with TKIs. We have examined whether changes in the normalised mean enhancement (a surrogate marker of tumour vessel density) correlate with response and resistance to anti-angiogenic therapy within individual metastases. We have assessed both the initial response to treatment (that is, between the baseline and the first on-treatment scan) and the development of acquired resistance to TKI treatment.

\section{MATERIALS AND METHODS}

Patients and lesions. The study group consisted of patients with mRCC commencing treatment with a TKI between July 2006 and October 2009 at the Mount Vernon Cancer Centre, Northwood, UK. Only patients with clear cell mRCC were included, following histological confirmation using tissue from either the primary or a metastatic lesion. In all cases, patients received TKIs as firstline therapy for metastatic disease. The TKIs used were sunitinib, pazopanib, cediranib or regorafenib. Details of the patient and lesion characteristics, the treatment setting and dosing regimens used are given in Tables 1 and 2. The activity of the TKIs utilised in this study ( $\mathrm{IC}_{50}$ for receptor inhibition with in vitro kinase assays) is shown in Table 3. Patients were required to have undergone at least two contrast-enhanced multidetector CT scans: one at baseline (pre-treatment) and one first on-treatment scan, typically following two cycles of therapy, using images acquired in the arterial phase of enhancement. Where available, lesions were also analysed longitudinally until disease progression, again using images acquired in the arterial phase of enhancement. Two of the patients included in the current study were also included in a previous retrospective analysis (Nathan et al, 2010).

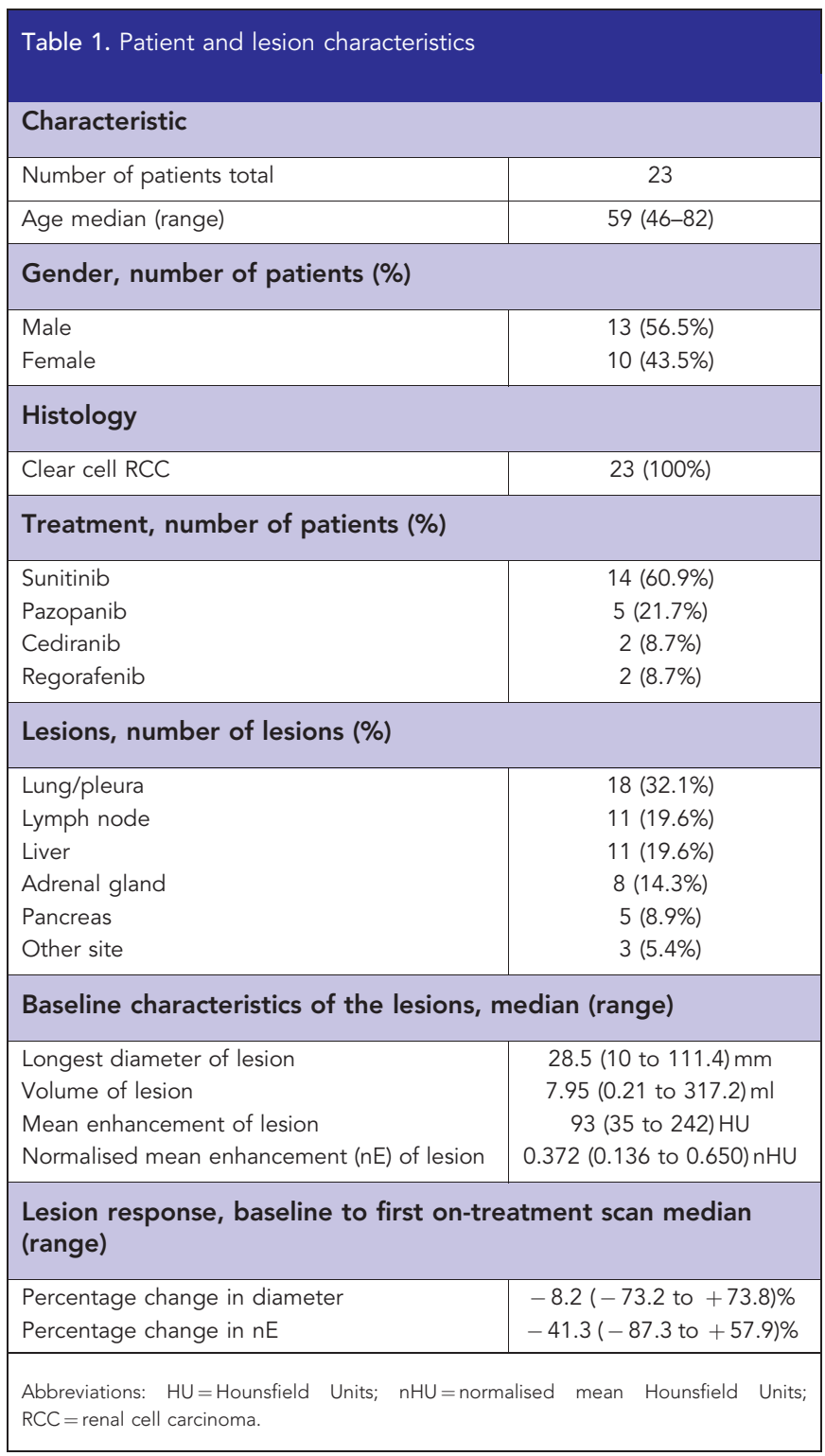


Table 2. Treatment setting and dosing regimen

\begin{tabular}{|l|l|l|l|l|l|}
\hline Drug & $\mathbf{n}$ & Manufacturer & Trial & Dose received & Schedule \\
\hline Sunitinib & 10 & Pfizer & NA & $50 \mathrm{mg}$ od & $28 \mathrm{~d}$ on/14d off \\
\hline Sunitinib & 3 & Pfizer & COMPARZ (NCT00720941) & $50 \mathrm{mg}$ od & $28 \mathrm{~d}$ on/14d off \\
\hline Sunitinib & 1 & Pfizer & TRIST (NCT00397345) & $50 \mathrm{mg}$ od & $28 \mathrm{~d}$ on/14d off \\
\hline Pazopanib & 5 & GlaxoSmithKline & COMPARZ (NCT00720941) & $800 \mathrm{mg}$ od & Continuous \\
\hline Cediranib & 2 & Astra Zeneca & D8480C00030 (NCT00423332) & $45 \mathrm{mg}$ od & Continuous \\
\hline Regorafenib & 2 & Bayer Healthcare Pharmaceuticals & DAST (NCT00664326) & $160 \mathrm{mg}$ od & $21 \mathrm{~d}$ on/7d off \\
\hline \multicolumn{2}{|l}{ Abbreviations: $d=$ days; NA = not applicable; od = oral dose. } \\
\hline
\end{tabular}

\begin{tabular}{|c|c|c|c|c|}
\hline & $\begin{array}{c}\text { Sunitinib } \\
\mathrm{IC}_{50} \pm \text { s.e.m. } \\
\text { (nM) }\end{array}$ & $\begin{array}{c}\text { Pazopanib } \\
\text { IC } \\
(\mathrm{nM}) \\
(\mathrm{nM})\end{array}$ & $\begin{array}{l}\text { Cediranib } \\
\mathrm{IC}_{50} \pm \text { s.e.m. } \\
\text { (nM) }\end{array}$ & $\begin{array}{l}\text { Regorafenib } \\
\mathrm{IC}_{50} \pm \mathrm{s} . \mathrm{d} \\
\text { (nM) }\end{array}$ \\
\hline VEGFR1 & 2 & 10 & $5 \pm 2$ & $13 \pm 0.4$ \\
\hline VEGFR2 & $9 \pm 2$ & 30 & $<1$ & $4.2 \pm 1.6$ \\
\hline VEGFR3 & 17 & 47 & $\leq 3$ & $46 \pm 10$ \\
\hline PDGFR $\alpha$ & $5-10$ & 71 & $36 \pm 8$ & NA \\
\hline PDGFR $\beta$ & $8 \pm 3$ & 84 & $5 \pm 1$ & $22 \pm 3$ \\
\hline c-kit & 13 & 74 & $2 \pm 0.1$ & $7 \pm 2$ \\
\hline Flt3 & $1-10$ & NA & $>1000$ & NA \\
\hline TIE2 & NA & 4520 & NA & $311 \pm 46$ \\
\hline FGFR1 & $830 \pm 120$ & 140 & $26 \pm 9$ & $202 \pm 18$ \\
\hline \multicolumn{5}{|c|}{$\begin{array}{l}\text { Abbreviations: } I C_{50}=\text { mean inhibitory concentration } 50 \text {; NA= data were not available; } \\
\text { PDGFR=platelet-derived growth factor receptor; TKIs = tyrosine kinase inhibitors; } \\
\text { VEGFR=vascular endothelial growth factor receptor. Table shows activity obtained within } \\
\text { in vitro kinase assays and is based on the values reported in the following studies: sunitinib } \\
\text { (Mendel et al, 2003; Cowey et al, 2010b), pazopanib (Kumar et al, 2007), cediranib (Wedge } \\
\text { et al, 2005), regorafenib (Wilhelm et al, 2011). When available, data are quoted with s.d. or } \\
\text { s.e.m. }\end{array}$} \\
\hline
\end{tabular}

Imaging. The following protocol was used routinely for all patients and at all time points reported in this study. For oral contrast, $250 \mathrm{ml}$ of EZ-CAT (EZEM, Bicester, UK) diluted in $750 \mathrm{ml}$ of water, was ingested $1 \mathrm{~h}$ before the CT was performed. An iodinated contrast agent was administered by the injection of $100 \mathrm{ml}$ of $350 \mathrm{mg} \mathrm{ml}^{-1}$ Optiray (Covidien Healthcare, Mansfield, MA, USA) at $4 \mathrm{ml} \mathrm{s}^{-1}$ via a pump injector, followed by a $50-\mathrm{ml}$ saline chaser at the same rate. The thorax and upper abdomen (from the supraclavicular fossa to the iliac crest) were imaged in the arterial phase (25 s after intravenous contrast agent administration). The abdomen and pelvis (from the dome of the diaphragm to the pubis) were then imaged in the portal venous phase (70 s after intravenous contrast agent administration). Patients underwent contrast-enhanced multidetector CT (Somatom Definition or Sensation 16, Siemens Healthcare, Forchheim, Germany) using the following acquisition parameters: $120 \mathrm{kV}$, effective mAs 150 (the thorax) or 200 (the abdomen and the pelvis) with dose modulation, pitch 1.2, detector configuration $24 \times 1.2 \mathrm{~mm}$, slice collimation $3 \mathrm{~mm}$, scan field of view 300 $450 \mathrm{~mm}$, matrix $512 \mathrm{~mm}$.

Image analysis. The image analysis was performed using data acquired in the arterial phase only. Target lesions with long axis of $\geqslant 10 \mathrm{~mm}$ were identified, and automated volume of interest software (syngoCT Oncology, Siemens Healthcare) was used to calculate parameters of interest. We calculated the volume of the lesion (following manual correction of the tumour outline) and the enhancement at each voxel (measured in Hounsfield Units, HU). From these data, the mean enhancement $(\mathrm{mE})$ for the whole tumour volume of interest was calculated. To take into account possible variation in the phase, delivery and distribution of the contrast agent between scans, the $\mathrm{mE}$ was normalised to the enhancement measured in the aorta $(\mathrm{aE})$. The $\mathrm{aE}$ was calculated by placing a region of interest within the aorta in the same axial plane as the lesion. The normalised mean enhancement (nE) for each lesion was then calculated as follows:

$\mathrm{nE}=\mathrm{mE} / \mathrm{aE}$

The software also calculated the maximum diameter of the lesion (measured in $\mathrm{mm}$ ). All measurements were conducted by $\mathrm{NV}$, a medical oncologist, and were confirmed by VG, an oncological radiologist with 15 years of experience in CT imaging. For the purpose of this study, no limit was placed on the number of target lesions included per patient or within an organ. The baseline enhancement and enhancement at the first on-treatment scan were expressed in terms of $\mathrm{nE}$ (normalised mean HU, $\mathrm{nHU}$ ). The lesion size at the baseline and at the first on-treatment scan was expressed in terms of the longest diameter $(\mathrm{mm})$. The change in lesion size was always expressed in terms of the percentage change in the longest diameter (\%). Change in enhancement was always expressed in terms of a percentage change in $\mathrm{nE}(\%)$. Time was expressed in terms of days.

Analysis of PFS. Progression-free survival (PFS) was defined as the number of days on therapy until therapy was discontinued because of disease progression, as documented in the patient's medical records. For the purposes of correlating features of the response with PFS on a per-patient basis, the baseline $\mathrm{nE}$, the percentage change in $\mathrm{nE}$ (between the baseline and the first on-treatment scan) and the percentage change in the lesion size (between the baseline and the first on-treatment scan) was averaged across all assessable lesions for each patient ( $n=1-7$ lesions per patient). An assessment of the response using modified Choi criteria (Nathan et al, 2010) was performed as follows: partial response $(\mathrm{PR} ; \geqslant 10 \%$ reduction in the lesion size and $\geqslant 15 \%$ reduction in the $\mathrm{nE}$ between the baseline and the first on-treatment scan), stable disease (SD; $<10 \%$ reduction in the lesion size and $<10 \%$ increase in size between the baseline and the first on-treatment scan, irrespective of change in enhancement) and progressive disease $(\mathrm{PD} ; \geqslant 10 \%$ increase in the lesion size between the baseline and the first on-treatment scan, irrespective of change in enhancement). Response by RECIST v1.1 was quantified as described (Eisenhauer et al, 2009). Kaplan-Meier analysis was then used to examine for correlations between (a) the baseline $\mathrm{nE}$ and PFS, (b) changes in the $\mathrm{nE}$ and PFS, (c) the response according to modified Choi criteria and PFS or (d) response according to RECIST and PFS. 
Generation of pseudo-coloured images. Grey scale axial images acquired by arterial phase CECT were pseudo-coloured using an image analysis software (Siemens Multimodality Work Platform, Siemens Healthcare). A colour look-up table called the 'PET rainbow' was applied so that each enhancement value (measured in HU) was assigned to an output colour. The dynamic range of the colour look-up table was set at a minimum of $-954 \mathrm{HU}$ and a maximum of $+422 \mathrm{HU}$. The resulting pseudo-coloured images are therefore colour-coded maps demonstrating the level of enhancement measured in each pixel.

Statistical analysis. The Pearson rank test was used to test for correlations between: (a) the baseline enhancement and change in lesion size between the baseline and the first on-treatment scan, (b) change in enhancement and change in lesion size between the baseline and the first on-treatment scan, (c) the baseline size and baseline enhancement, (d) size at the first on-treatment scan and enhancement at the first on-treatment scan, (e) change in size and days elapsed between defined time points, ( $f$ ) change in enhancement and days elapsed between defined time points. The log-rank test was used to test for significant differences in PFS when patients were stratified according to the baseline enhancement, change in enhancement, modified Choi response criteria and RECIST. For lesions that acquired resistance to therapy, the Mann-Whitney $U$-test was used to test whether the change in size and the change in enhancement was significant when comparing lesions that underwent PR as best response with lesions that underwent $\mathrm{SD}$ as best response. $P$ values $\leqslant 0.05$ were considered to be statistically significant.

\section{RESULTS}

Details of the study population. A total of 56 lesions from 23 patients were analysed, with a median of 2 lesions (and a range of 1-7) per patient. The baseline CT scan was performed at a median of 14 (4-38) days before commencing the therapy. The first on-treatment scan was performed at a median of 72 (33-113) days after starting treatment. Longitudinal monitoring of lesions, where patients had a baseline scan, followed by two or more on-treatment scans, was available for 21 lesions amongst 13 patients. Amongst these 21 lesions, we identified 10 lesions amongst seven patients that could be followed until disease progression. It was not possible to follow lesions until disease progression in the remaining patients because of the following reasons: the patient stopped taking the drug for reasons other than disease progression; the lesion was no longer visible or measurable; subsequent scans were non-contrast (owing to worsening renal function precluding the IV contrast agent administration: renal impairment with a serum creatinine $>120 \mu \mathrm{moll}^{-1}$ or eGFR $<60 \mathrm{ml} \mathrm{min}^{-1}$ ); or the patient was lost to follow-up.

Correlation of imaging features during the initial response to therapy. To address the initial response to therapy, lesion size and lesion enhancement were measured at baseline and at the first on-treatment scan for all 56 lesions in the study. For measurement of the lesion size, we used the longest diameter of the lesion. For measurements of enhancement, the mean enhancement (mE) present across the entire volume of the lesion was calculated. This was then normalised to the enhancement in the aorta $(\mathrm{aE})$, to give the normalised mean enhancement $(\mathrm{nE})$ for the entire lesion. Change in lesion size and change in $\mathrm{nE}$ were both expressed in terms of percentage change from baseline.

We found no correlation between the baseline $\mathrm{nE}$ and reduction in lesion size (Figure 1A). However, we found a strong correlation between reduction in $\mathrm{nE}$ and reduction in lesion size (Figure 1B, $r=0.654, P<0.0001)$. A possible explanation for this observation is that smaller tumours merely have lower enhancement. To address this, we examined whether the absolute lesion size (longest lesion diameter) correlated with the amplitude of $\mathrm{nE}$. However, no correlation between the absolute lesion size and $\mathrm{nE}$ was found either at the baseline or at the first on-treatment scan (Supplementary Figure 1A and B). The correlation between reduction in $\mathrm{nE}$ and reduction in tumour size might also reflect differences between patients in terms of the time elapsed between scans. However, no correlations were found between either the change in size or the change in $\mathrm{nE}$ and the duration of time elapsed (a) from the baseline scan to the start of treatment, (b) from the start of treatment to the first on-treatment scan and (c) from the baseline scan to the first on-treatment scan (Supplementary Figures 2-4).

Correlation of imaging features with PFS. Data on PFS were available for 22 of the 23 patients in the study. The median PFS was 298 days (a range of 74-1450), which is comparable to that of previously published cohorts (Sternberg et al, 2010; Motzer et al, 2012a,b). We examined whether the baseline $\mathrm{nE}$ or the change in $\mathrm{nE}$ (from baseline to the first on-treatment scan) correlated with PFS. No statistically significant difference in the median PFS was observed when patients with a baseline $\mathrm{nE}$ above the median value $(>0.39 \mathrm{nHU})$ were compared with patients with a baseline $\mathrm{nE}$ below the median value ( $<0.39 \mathrm{nHU}$; Figure $1 \mathrm{C})$. No statistically significant difference in the median PFS was observed when patients having a percentage change in $\mathrm{nE}$ that was above the median value $(>51.1 \%)$ were compared with patients having a percentage change in $\mathrm{nE}$ that was below the median value $(<51.1 \%$; Figure $1 \mathrm{D})$. We also applied the modified Choi criteria, which take into account both the change in size and enhancement, to categorise patient responses (Nathan et al, 2010). Using these criteria, 11 patients achieved a PR, 9 patients achieved SD and 2 patients had progressive disease. The difference in median PFS between patients experiencing SD (using modified Choi criteria) and those experiencing PR (using modified Choi criteria) was statistically significant (211 vs 508 days, $P=0.05$, Figure 1E). In contrast, when patients were stratified using RECIST criteria, no significant difference in median PFS between patients experiencing $\mathrm{SD}(n=17)$ and those experiencing PR $(n=3$ patients) was observed $(P=0.9)$.

Subgrouping of individual lesions based on change in size and change in enhancement. We then examined whether individual lesions could be grouped together into categories based on both change in size and change in enhancement. To do this, we devised criteria that categorised lesions into one of four different 'response subgroups' (Figure 2 and Table 3).

Seven lesions (12.5\%) underwent what could be described as a PR according to conventional RECIST criteria, that is, a decrease in the length of the longest diameter of the individual lesion by $\geqslant 30 \%$. All seven of these lesions also underwent a corresponding large drop in enhancement (range of -63.1 to $-87.3 \%$ ). Therefore, this represents a subgroup of lesions (response subgroup 1) that undergoes both a good vascular response $(\geqslant 50 \%$ reduction in $\mathrm{nE})$ and significant tumour shrinkage $(\geqslant 30 \%$ decrease in size; Figure 2). These lesions were spread across a range of anatomical sites: the liver (two), lymph node (two), adrenal gland (one), lung (one) and pancreas (one). Imaging data captured before and after treatment from two lesions in response subgroup 1 is shown in Figure $3 \mathrm{~A}$ and B.

Forty-three lesions (76.8\%) could be classified as SD according to RECIST; that is, they exhibited $<30 \%$ decrease in the length of the longest diameter, but $<20 \%$ increase in the length of the longest diameter for the individual lesion. Here, the change in enhancement was more varied (a range of -79.5 to $+8.8 \%$ ). Interestingly, 14 of these lesions underwent a large drop in enhancement (a range of -52.3 to $-79.5 \%$ ), which is a similar range to that of the change observed in the response subgroup 1. Therefore, in this second subgroup of lesions (response subgroup 2), despite undergoing a good vascular response $(\geqslant 50 \%$ reduction in $\mathrm{nE})$, 

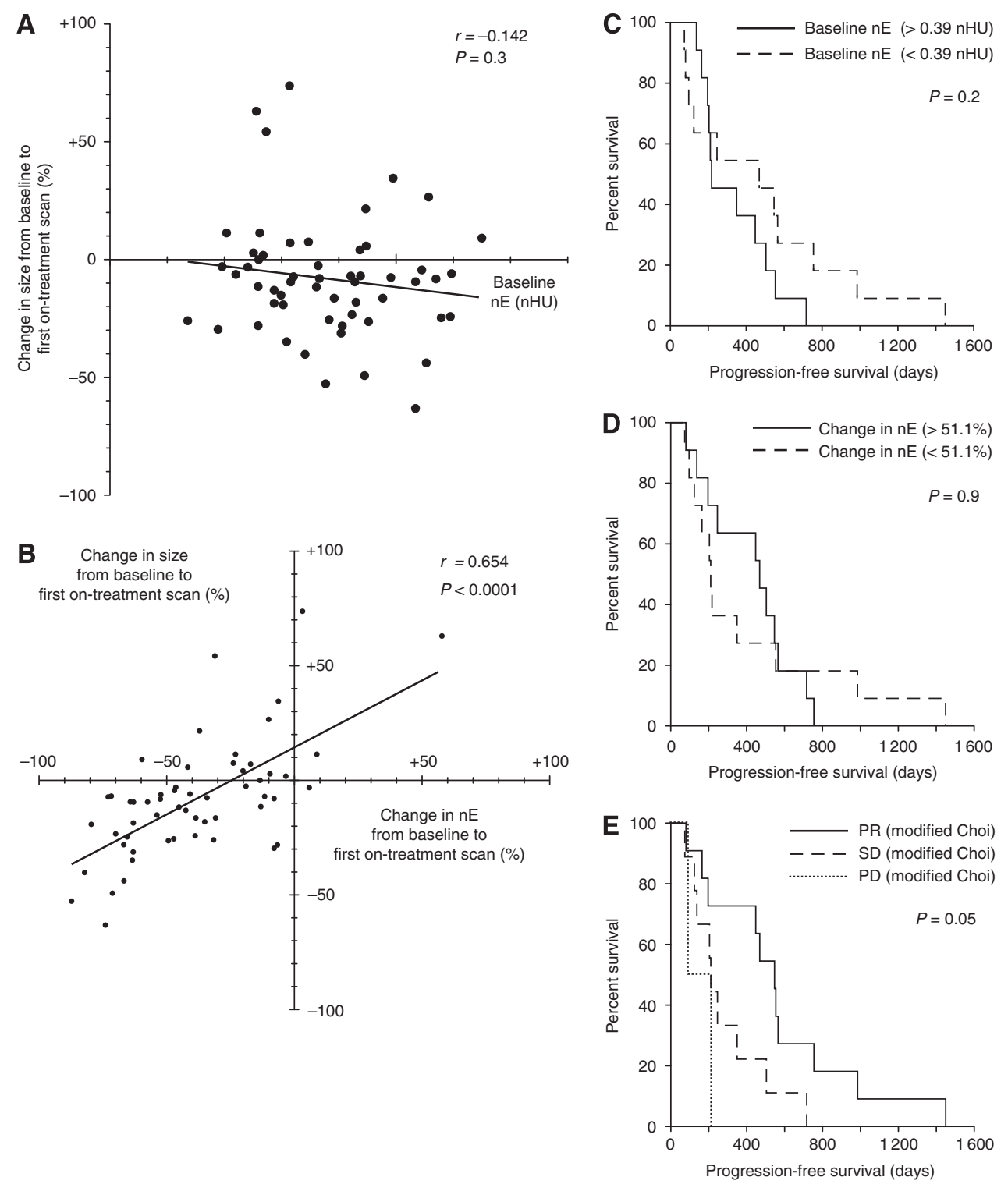

Figure 1. Correlation of imaging features with change in lesion size and patient outcome. (A) Analysis of correlation between the baseline $n E$ and the percentage change in the lesion size (baseline to the first on-treatment scan). Baseline $\mathrm{nE}$ is measured in normalised mean Hounsfield Units (nHU). ( $r=-0.142, P=0.3$ ). (B) An analysis of the correlation between the change in $n E$ (baseline to the first on-treatment scan) and percentage change in lesion size (baseline to the first on-treatment scan; $r=0.654, P<0.0001$ ). Change in $\mathrm{nE}$ is measured in percentage. (C) Kaplan-Meier analysis: PFS of patients with baseline $\mathrm{nE}$ greater than the median $(>0.39 \mathrm{nHU})$ and baseline $\mathrm{nE}$ less than the median $(<0.39 \mathrm{nHU}), P=0.2$. (D). Kaplan-Meier analysis: PFS of patients with the change in $\mathrm{nE}$ greater than the median $(>51.1 \%)$ and change $\mathrm{nE}$ less than the median $(<51.1 \%), P=0.9$. (E) Kaplan-Meier analysis: PFS of patients with a partial response (PR), stable disease (SD) or progressive disease (PD) according to modified Choi criteria, $P=0.05$.

only disease stabilisation was achieved $(<30 \%$ decrease in size, but $<20 \%$ increase in size; Figure 2). The anatomical locations of these lesions were: the pancreas (four), lung/pleura (three), liver (two), lymph node (two), adrenal gland (one), primary (one) and renal bed (one). Imaging data captured before and after treatment from one lesion in response subgroup 2 are shown in Figure 3C (and a second example is shown in Figure 4F).

In the remaining 29 lesions that could be classified as SD using RECIST, the change in enhancement was more modest (with a range of -49.3 to $+8.8 \%$ ). This response subgroup 3 is characterised by a poor vascular response $(<50 \%$ reduction in $\mathrm{nE})$ and disease stabilisation $(<30 \%$ decrease in size, but $<20 \%$ increase in size; Figure 2). The anatomical locations of these lesions were: lung/ pleura (11), lymph node (7), adrenal gland (5), liver (5) and chest wall (1). Imaging data captured before and after treatment from two lesions in response subgroup 3 are shown in Figure 3D and E.
Six lesions (10.7\%) were classed as progressive disease by RECIST $(\geqslant 20 \%$ increase in the length of the longest diameter for the individual lesion). In these lesions, the change in enhancement was also variable (a range of -37.1 to +57.8 ), but there was significant overlap with the change observed in response subgroup 3 . Therefore, this is a subgroup of lesions (response subgroup 4) characterised by a poor vascular response $(<50 \%$ reduction in $\mathrm{nE})$ and disease progression ( $\geqslant 20 \%$ increase in size; Figure 2$)$. The anatomical locations of these lesions were: lung/pleura (three), liver (two) and adrenal gland (one). Imaging data captured before and after treatment from one lesion in response subgroup 4 are shown in Figure 3F (and a second example is shown in Figure 4G).

Heterogeneity of response between lesions in the same patient. We selected the five patients in our study who had four or more measurable lesions at baseline and examined for 


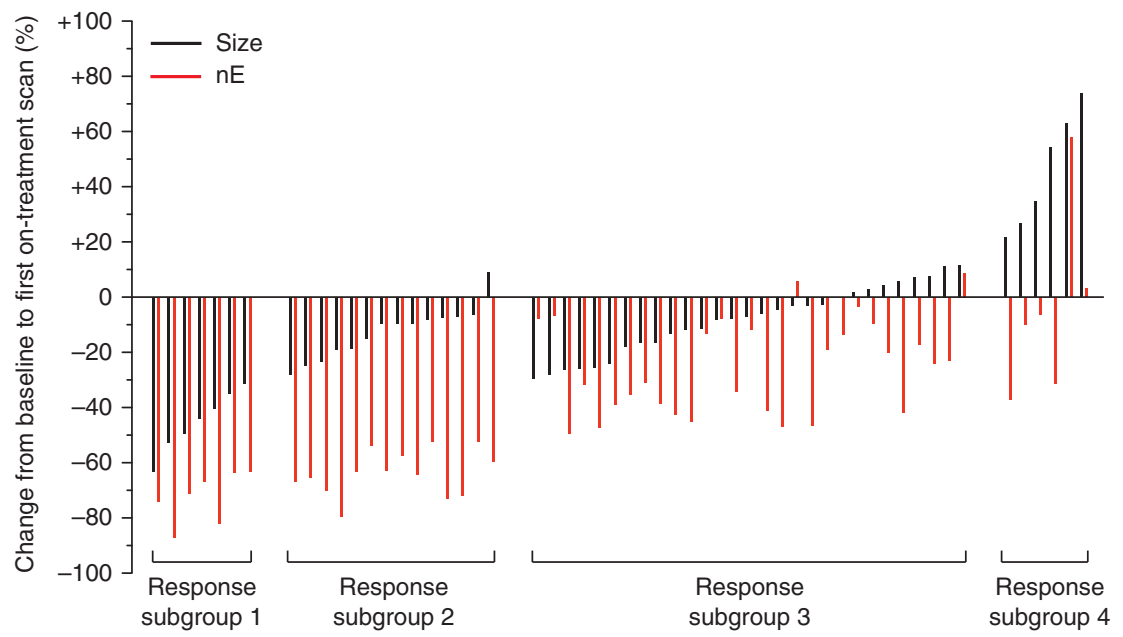

Figure 2. Categorisation of individual lesions into four response subgroups. Waterfall plot shows the percentage change in lesion size (black) and the percentage change in normalised mean enhancement ( $\mathrm{nE}$; red) between the baseline and the first on-treatment scan for each of the 56 lesions in the study. Criteria based on the change in size and the change in $\mathrm{nE}$ are used to classify response: response subgroup 1 ( $\geqslant 30 \%$ reduction in size and $\geqslant 50 \%$ reduction in enhancement), response subgroup $2(<30 \%$ reduction in size, but $<20 \%$ increase in size and $\geqslant 50 \%$ reduction in enhancement), response subgroup $3(<30 \%$ reduction in size, but $<20 \%$ increase in size and $<50 \%$ reduction in enhancement) and response subgroup 4 ( $\geqslant 30 \%$ increase in size and $<50 \%$ reduction in $\mathrm{nE})$.

heterogeneity of response between lesions. To define heterogeneity of response, lesions were classified as belonging to one of the four previously defined response subgroups (see Table 4). Patients were defined as undergoing a homogenous response if all of their lesions could be classified as belonging to the same response subgroup. Patients were defined as undergoing a heterogeneous response if different lesions were classified as belonging to different response subgroups. In two out of the five patients, a homogeneous response to therapy was observed, with all four lesions belonging to response subgroup 3 (Figure $4 \mathrm{~A}$ and $\mathrm{B}$ ). However, a heterogeneous response was demonstrable in patients 3,4 and 5 (Figure 4C-E). For example, in the fifth patient, lesion 1, undergoing a good vascular response $(\geqslant 50 \%$ decrease in $\mathrm{nE})$ and disease stabilisation (Figure 4E), was classified as belonging to subgroup 2. Imaging data obtained at the baseline and at the first on-treatment scan are presented for lesion 1 (Figure $4 \mathrm{~F}$ ). However, lesions 2-5, undergoing a poor vascular response $(<50 \%$ decrease in $\mathrm{nE})$ and disease stabilisation (Figure 4E), were classified in subgroup 3. Finally, lesions 6 and 7 were classified in subgroup 4, undergoing a poor vascular response $(<50 \%$ reduction in enhancement) and disease progression (Figure 4E). Imaging data obtained at the baseline and at the first on-treatment scan are presented for lesion 7 (Figure 4G).

Longitudinal assessment of lesions until progression. A significant majority of renal cell carcinoma metastases acquire resistance to TKIs following a period of disease control. Where the data were available, we monitored individual lesions longitudinally until they progressed. A total of 10 lesions across seven patients met our criteria for progressive disease $(\geqslant 20 \%$ increase in size from nadir). In five of these lesions, the best response before progression was classified as a PR (according to RECIST criteria), with the anatomical sites being the liver (two), lymph node (two) and pancreas (one). In the remaining five lesions, the best response before progression was classified as SD according to RECIST, with the anatomical sites being the lymph node (three), adrenal gland (one) and lung (one).

An example of longitudinal data from a lesion, with best response classified as $\mathrm{PR}$, that subsequently progressed on therapy is presented in Figure 5A and B. The initial reduction in tumour size between the baseline and the first on-treatment scan was paralleled by a substantial reduction in enhancement $(\geqslant 50 \%$ reduction in $\mathrm{nE}$; Figure $5 \mathrm{~A})$. It is noteworthy that compared with the baseline scan, the lesion converts into a more homogenous, hypoattenuating appearance at 41 days after the commencement of the treatment (Figure 5B). The lesion's nadir was recorded in a scan obtained after 249 days of therapy, at which time point the $\mathrm{nE}$ recorded still remained low compared with that of the baseline (Figure 5A). However, a further scan obtained after 326 days of therapy indicated that the lesion had progressed $(\geqslant 20 \%$ increase in size from nadir). The progression was accompanied by a dramatic increase in the $\mathrm{nE}$ of the lesion (Figure 5A). Note the presence of hyperattenuating regions throughout the tumour at this time point (Figure 5B). A final scan obtained after 524 days of therapy confirmed that the lesion continued to progress and that the lesion enhancement remained elevated (Figure 5A and B). Therefore, the acquired resistance to therapy in this lesion was clearly accompanied by re-vascularisation.

An example of longitudinal data from a lesion, with best response classified as SD that subsequently progressed on therapy, is presented in Figure 5C and D. Here, despite a substantial reduction in enhancement between the baseline and the first on-treatment scan $(\geqslant 50 \%$ reduction in $\mathrm{nE}$ ), only a modest reduction in tumour size was observed. The lesion's nadir was recorded in a scan obtained after 109 days of therapy, at which time point the $\mathrm{nE}$ also remained reduced relative to the baseline. Interestingly, although disease progression was observed on the final scan obtained after 249 days of therapy, the parallel increase in $\mathrm{nE}$ was only modest. Given this observation, we plotted the change in size and change in $\mathrm{nE}$ between the baseline and nadir and between the nadir and progression for all lesions that underwent $\mathrm{PR}$ as best response, and for all lesions that underwent $\mathrm{SD}$ as best response (Figure $5 \mathrm{E}-\mathrm{H}$ ). The change in size between the baseline and nadir was significantly greater in the $\mathrm{PR}$ group compared with the SD group (Figure 5E; $P=0.01$ ). There was a trend towards a greater reduction in $\mathrm{nE}$ in the $\mathrm{PR}$ group compared with the SD group (Figure 5F; $P=0.06$ ). During progression, the increase in size observed in the PR group was not statistically different from the SD group (Figures $5 \mathrm{G}, P=0.3$ ). However, the increase in $\mathrm{nE}$ recorded during progression, even among this small number of lesions, was significantly greater in the $\mathrm{PR}$ group compared with the SD group (Figures $5 \mathrm{H}, P=0.008$ ). Therefore, rebound re-vascularisation during progression was more 

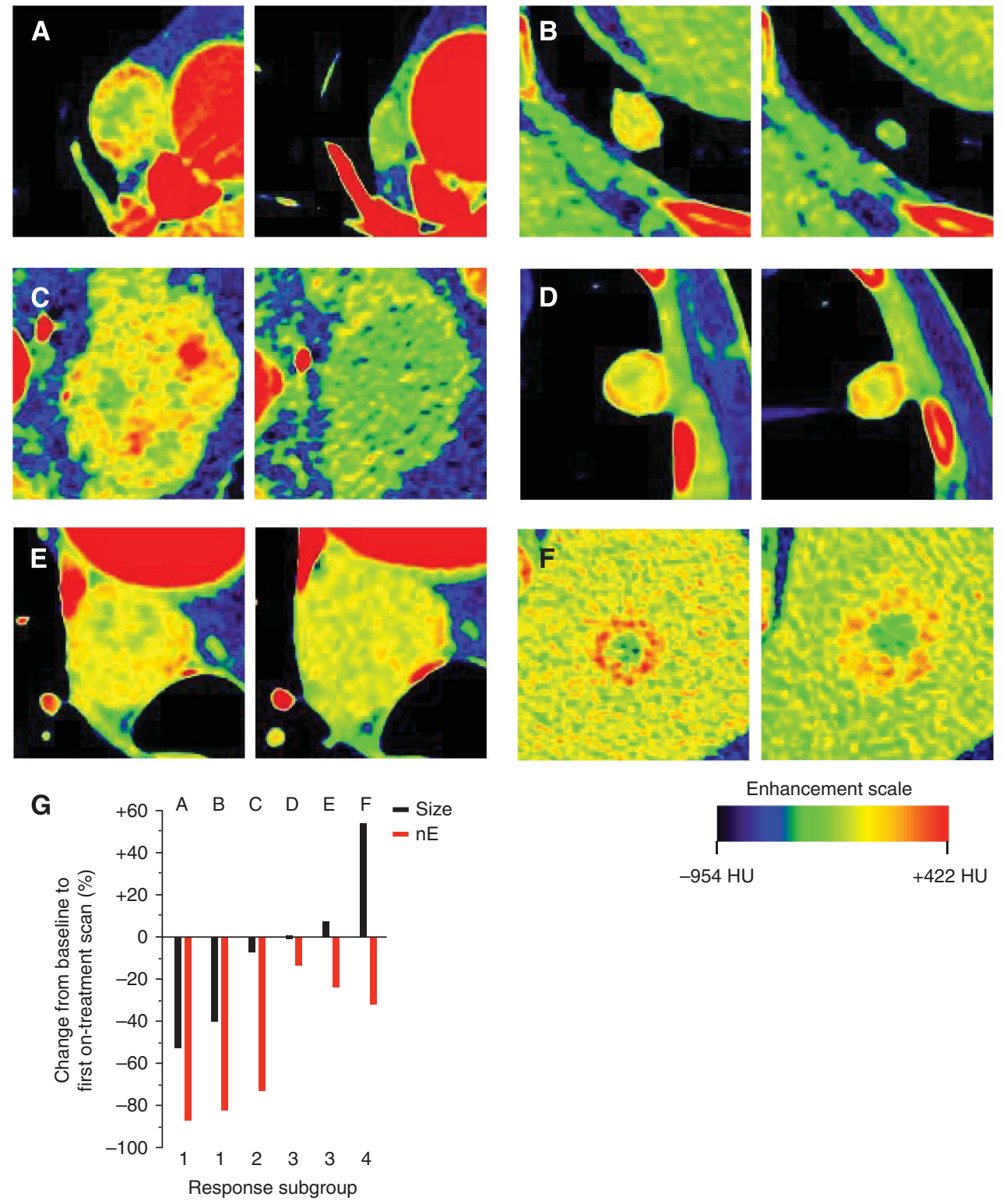

Figure 3. Representative axial images from individual lesions at the baseline and the first on-treatment scan. Pseudo-coloured arterial phase contrast-enhanced CT images of individual lesions from response subgroups 1, 2, 3 and 4 are shown. In each panel, the left hand image is the baseline scan and the right hand image is the first on-treatment scan. (A) Hilar node metastasis from a 57-year-old man treated with pazopanib (response subgroup 1). (B) Lung metastasis from a 79-year-old woman treated with pazopanib (response subgroup 1). (C) Pancreatic metastasis from an 82-year-old man treated with pazopanib (response subgroup 2). (D) Pleural metastasis from a 52-year-old woman treated with sunitinib (response subgroup 3). (E) Pre-tracheal lymph node metastasis from a 64-year-old man treated with sunitinib (response subgroup 3). (F) Liver metastasis from a 65-year-old man treated with cediranib (response group 4). (G) Waterfall plot shows the percentage change in lesion size (black) and the percentage change in $\mathrm{nE}$ (red) between the baseline and first on-treatment scan for each of the lesions depicted in panels (A-F).

significant in lesions that underwent $\mathrm{PR}$ as the best response than it was in lesions that underwent SD as best response. Importantly, we found no correlation between the increase in $\mathrm{nE}$ from nadir to progression and the increase in tumour size (Supplementary Figure 5A). Moreover, the time elapsed between scans did not correlate with the increase in $\mathrm{nE}$ from nadir to progression (Supplementary Figure 5B).

As we also recorded six lesions that progressed during the initial response to therapy, it was of interest to examine whether, as a group, these lesions also underwent an overall increase in enhancement during their progression. Interestingly, in contrast to the scenario of acquired resistance, where there was an overall increase in the enhancement during progression (mean change in $\mathrm{nE}$ between nadir to progression $=+344 \pm 107 \%$ in lesions undergoing $\mathrm{PR}$ as the best response, mean change in $\mathrm{nE}$ between nadir to progression $=+22 \pm 11 \%$ in lesions undergoing SD as best response, Figure $5 \mathrm{H}$ ), there was no overall increase in enhancement at progression in lesions that underwent PD as the best response (mean change in $\mathrm{nE}$ from baseline to progression $=-5.4 \pm 15 \%)$.

\section{DISCUSSION}

Understanding the mechanisms that determine response and resistance to anti-angiogenic agents is a key goal, with potential relevance to a broad range of cancers. Here, we utilised the amplitude of $\mathrm{nE}$ on arterial phase CECT imaging as a surrogate marker of tumour vessel density in order to explore how changes 

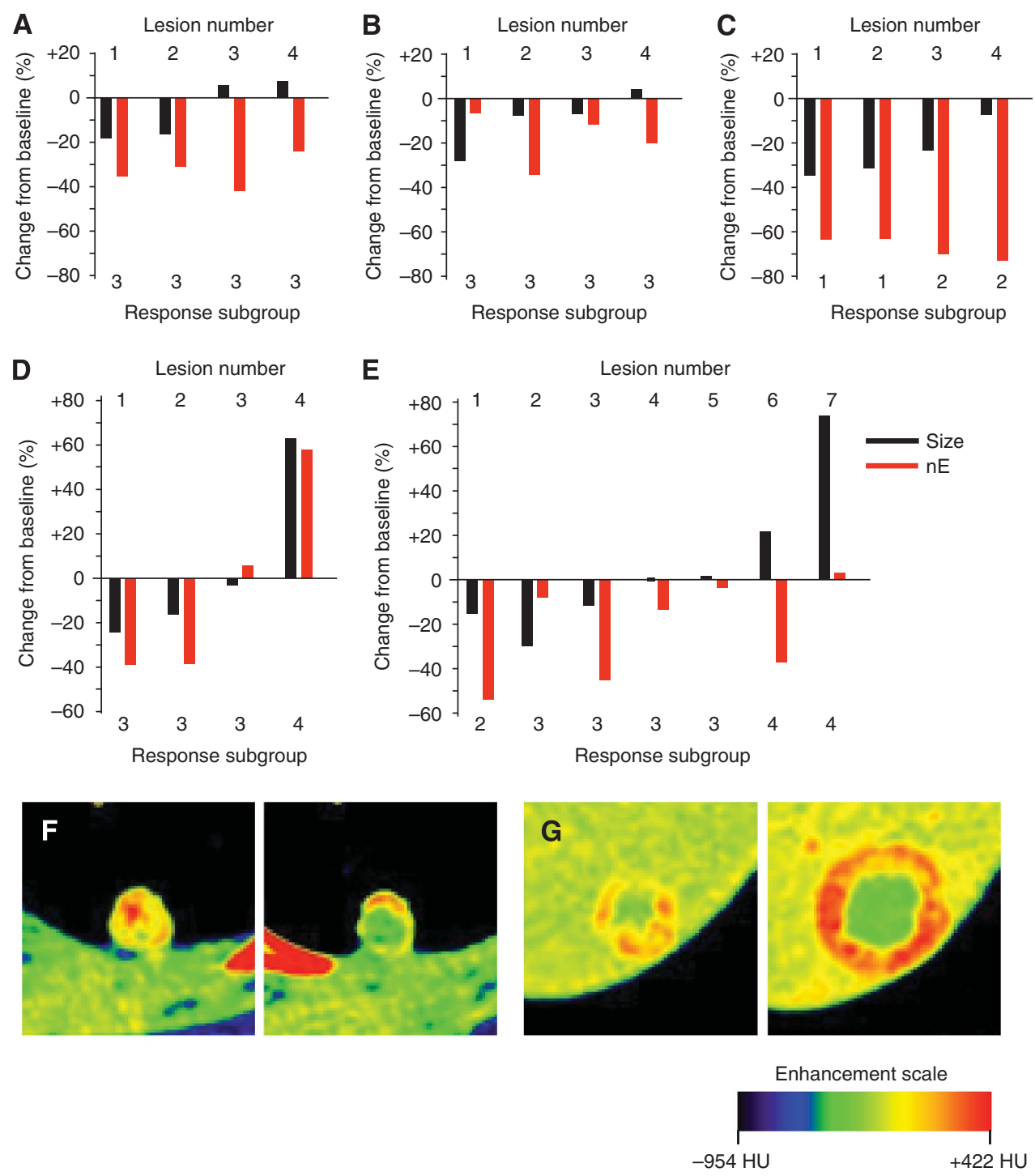

Figure 4. Heterogeneity of response between different lesions in the same patient. (A-E) The responses of different lesions within the same patient were compared. Waterfall plots showing the percentage change in lesion size (black) and the percentage change in $\mathrm{nE}$ (red) between the baseline and first on-treatment scan for five patients. Lesions are assigned identification numbers from 1 to 4 or 1 to 7 , as appropriate, and are classified according to response subgroup 1, 2, 3 or 4 as appropriate. (A) A 69-year-old man treated with sunitinib: lesions 1-3 are lung metastases and lesion 4 is a mediastinal lymph node metastasis. (B) A 57-year-old man treated with sunitinib: lesions 1,3 and 4 are liver metastases and lesion 2 is a hilar lymph node metastasis. (C) An 82-year-old man treated with pazopanib: lesion 1 is a hilar lymph node metastasis, lesions 2 and 3 are head of pancreas metastases and lesion 4 is a tail of pancreas metastasis. (D) A 69-year-old woman treated with sunitinib: lesions 1-4 are all lung metastases. (E) A 52-year-old woman treated with sunitinib: lesions 1-6 are lesions present in either the pleura or lung, whereas lesion 7 is a liver metastasis. ( $\mathbf{F}$ and $\mathbf{G})$ Pseudo-coloured arterial phase contrast-enhanced CT images of two lesions from the patient featured in panel $\mathbf{E}$ are shown. The baseline and first on-treatment scans of lesion 1, a pleural metastasis (F), and of lesion 7, a liver metastasis (G), are shown.

in tumour vessel density correlate with the response and resistance to angiogenic therapy in mRCC patients. In the following discussion, we place these observations in context with regard to other published work in this area and with regard to understanding the mechanisms of response and resistance to anti-angiogenic agents.

We did not find any relationship between baseline lesion enhancement and change in lesion size or between baseline lesion enhancement and PFS, suggesting that baseline tumour vessel density does not determine response. As the mechanisms that determine response and resistance to anti-angiogenic agents are complex (Bergers and Hanahan, 2008; Ebos et al, 2009; BottsfordMiller et al, 2012; Sennino and McDonald, 2012), it is perhaps not surprising that tumour vessel density at baseline does not predict response to anti-angiogenic therapy. However, in contrast to our findings, some other studies have reported an association between baseline vascular parameters and response to TKIs in mRCC. In patients treated with either sunitinib or sorafenib, Han et al (2010) reported a positive correlation between high pre-treatment enhancement on CECT and both tumour size reduction and PFS, whereas Fournier et al (2010) reported a positive correlation between high tumour perfusion, measured by dynamic contrastenhanced CT, and objective response. In addition, two DCI-MRI studies showed that high $K^{\text {trans }}$ at baseline was positively correlated with longer PFS in patients treated with sorafenib (Flaherty et al, 2008; Hahn et al, 2008). However, there were technical differences between these studies and the current study that may explain the discrepancy. First, in three of these studies (Flaherty et al, 2008; Hahn et al, 2008; Fournier et al, 2010), the imaging modality employed was different to the method used here. Second, all four 
Table 4. Response subgroups 1, 2, 3 and 4: criteria for subgrouping of individual lesions based on change in size and change in enhancement

\begin{tabular}{|l|l|}
\hline & Response criteria for individual lesions \\
\hline Response subgroup 1 & $\begin{array}{l}\geqslant 30 \% \text { reduction in size } \\
\geqslant 50 \% \text { reduction in } \mathrm{nE}\end{array}$ \\
\hline Response subgroup 2 & $\begin{array}{l}<30 \% \text { reduction in size, and }<20 \% \text { increase in size } \\
\geqslant 50 \% \text { reduction in } \mathrm{nE}\end{array}$ \\
\hline Response subgroup 3 & $\begin{array}{l}<30 \% \text { reduction in size, and }<20 \% \text { increase in size } \\
<50 \% \text { reduction in } \mathrm{nE}\end{array}$ \\
\hline Response subgroup 4 & $\begin{array}{l}\geqslant 20 \% \text { increase in size } \\
<50 \% \text { reduction in } \mathrm{nE}\end{array}$ \\
\hline Abbreviation: $\mathrm{nE}=$ normalised mean enhancement.
\end{tabular}

studies (Flaherty et al, 2008; Hahn et al, 2008; Fournier et al, 2010; Han et al, 2010) measured the enhancement within a single ROI on axial images without normalisation to the cardiac output, whereas we measured the enhancement from the entire tumour volume and normalised our measurements to the cardiac output.

We analysed the change in enhancement and change in size that occurred within individual lesions between the baseline and the first on-treatment scan. We found that reduction in tumour enhancement in response to TKI treatment was strongly correlated with a reduction in lesion size. Interestingly, two previously published imaging studies show that the reduction in enhancement measured using CECT is correlated with tumour shrinkage and longer PFS in mRCC patients (Cowey et al, 2010a; Smith et al, 2010a). Moreover, a reduction in equivalent tumour vascular parameters measured using other imaging modalities has been shown to correlate with PFS (Flaherty et al, 2008) or OS (Lassau et al, 2010) in mRCC patients. Taken together, these data suggest that the ability of these agents to induce a vascular response is associated with tumour shrinkage and clinical benefit. Here, we have also found that modified Choi response criteria, which take into account early changes in both enhancement and size, can discriminate patients with a longer PFS from patients with a shorter PFS. This finding is in agreement with four other imaging studies demonstrating that variants of the Choi response criteria can predict benefit in mRCC patients treated with TKIs (Nathan et al, 2010; van der Veldt et al, 2010; Smith et al, 2010b; Krajewski et al, 2011).

In our study, we also classified individual lesions into four different response subgroups, using criteria that were based on both the vascular response and the change in size observed after treatment (Table 4, Figure 6A-D). For example, lesions in response subgroup 1 underwent a good vascular response $(\geqslant 50 \%$ reduction in $\mathrm{nE})$ that was accompanied by significant tumour shrinkage (Figure 6A). However, in response subgroup 2, a good vascular response $(\geqslant 50 \%$ reduction in $\mathrm{nE}$ ) translated into only stabilisation of disease (Figure 6B). It is not currently clear why a good vascular response can result in significant tumour shrinkage or just disease stabilisation, but preclinical work may provide some clues. For example, there are mechanisms that permit tumour cells to survive even when the vascular supply is significantly reduced. These survival mechanisms include a reduced propensity for tumour cells to die under conditions of stress and may be driven by genetic aberrations such as the loss of p53 function (Yu et al, 2001, 2002). More recent work shows that tumours exposed to anti-VEGF therapy show signs of increased autophagy (Hu et al, 2012a,b; Guo et al, 2013), altered metabolism (Nardo et al, 2011; Welti et al, 2012; Zulato et al, 2012; $\mathrm{Xu}$ et al, 2013) and adaptation to hypoxia (McIntyre et al, 2012; Rapisarda and Melillo, 2012). These may all constitute potential mechanisms via which tumours adapt and survive, despite a reduction in their vascular supply. Therefore, adaptation of tumour cells to loss of a vasculature may be an important mechanism of intrinsic resistance to anti-angiogenic therapy and may explain, at least in part, why a good vascular response does not always result in significant tumour shrinkage.

Lesions in response subgroups 3 and 4 were characterised by a weaker vascular response ( $<50 \%$ reduction in $\mathrm{nE}$ ) and only achieved disease stabilisation (subgroup 3, Figure 6C) or in fact progressed (subgroup 4, Figure 6D). This weaker vascular response suggests that a significant proportion of vessels survived TKI treatment in these lesions, which may explain why more significant tumour shrinkage was not observed. The TKIs utilised in this study are proposed to target tumour angiogenesis principally by blocking the pro-angiogenic signalling of VEGF and PDGF, growth factors that promote the growth and survival of new tumour vessels. However, there is preclinical and clinical evidence for various mechanisms that may limit the ability of TKIs to suppress tumour angiogenesis. For example, tumour vessels are known to undergo a maturation process that renders them insensitive to VEGF inhibition, and tumours that have a large fraction of mature vessels are therefore less probable to respond to anti-angiogenic TKIs (Bergers and Hanahan, 2008; Sitohy et al, 2011, 2012). Moreover, there is evidence that some metastatic tumours obtain access to a vasculature via alternative non-angiogenic mechanisms, including vessel co-option, vascular mimicry or vessel intussusception (Dome et al, 2007; Leite de Oliveira et al, 2011). Interestingly, vessel co-option has been described in brain, lung and liver metastases and is a process whereby, instead of inducing new blood vessel formation, tumours co-opt existing local blood vessels as they invade into the surrounding host tissue (Pezzella et al, 1996; Holash et al, 1999; Vermeulen et al, 2001; Leenders et al, 2004; Sardari Nia et al, 2007). Therefore, another important source of intrinsic resistance to anti-angiogenic therapy may be the presence of tumour vessels that are not affected by the treatment due to mechanisms such as those described above. This may explain the poor response observed in response subgroups 3 and 4 .

Here, we also document that different responses to therapy can occur in different lesions within the same patient. This observation is important because it suggests that, when exposed to the same anti-angiogenic therapy, some metastases can respond well, whereas others may simultaneously progress. This poses challenges in terms of optimal patient management and continuation of therapy, and may herald early treatment failure. The mechanisms that underlie this heterogeneity of response are unclear. Deep sequencing studies have demonstrated the existence of genetic heterogeneity between different mRCC lesions within the same patient (Gerlinger et al, 2012), suggesting that tumours in different metastatic sites in the same patient may have different biology. If this includes (a) differences in their ability to adapt to loss of a vasculature, and/or (b) differences in the sensitivity of their vasculature to TKIs, this may give rise to heterogeneity of response to anti-angiogenic therapy between different lesions. It will be important to understand the mechanisms that underlie this heterogeneity in order to improve on the efficacy of current anti-angiogenic treatment approaches.

The development of acquired resistance to anti-angiogenic agents is universally observed. Here, we clearly demonstrate that acquired resistance in patients is accompanied by re-vascularisation. Smith et al (2010a) have reported a similar observation. The mechanism that permits this re-vascularisation has yet to be confirmed. However, upregulation of other secreted pro-angiogenic factors, such as FGF2, IL8 or HGF, has been reported in acquired resistance and may act to stimulate tumour angiogenesis even in the presence of ongoing VEGF receptor blockade (Casanovas et al, 2005; Huang et al, 2010; Kopetz et al, 2010; Shojaei et al, 2010; Welti et al, 2011; Porta et al, 2012). These data highlight the possibility that acquired resistance might be circumvented if a more sustained inhibition of angiogenesis 


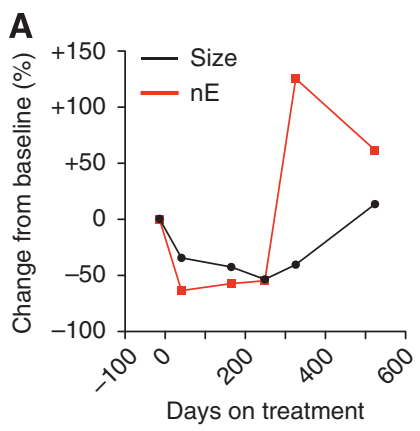

B

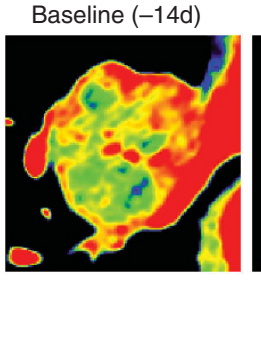

Treated $(+41 d)$
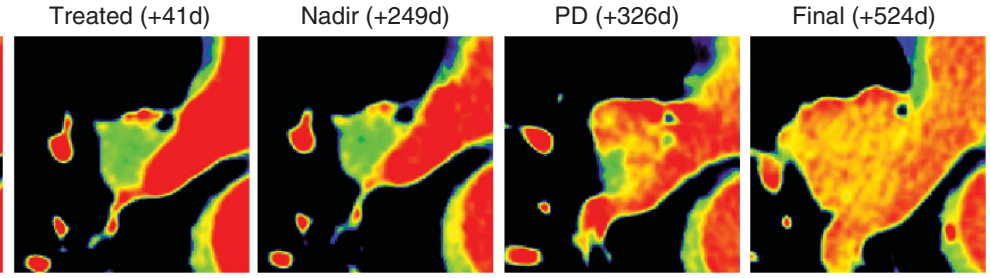

D
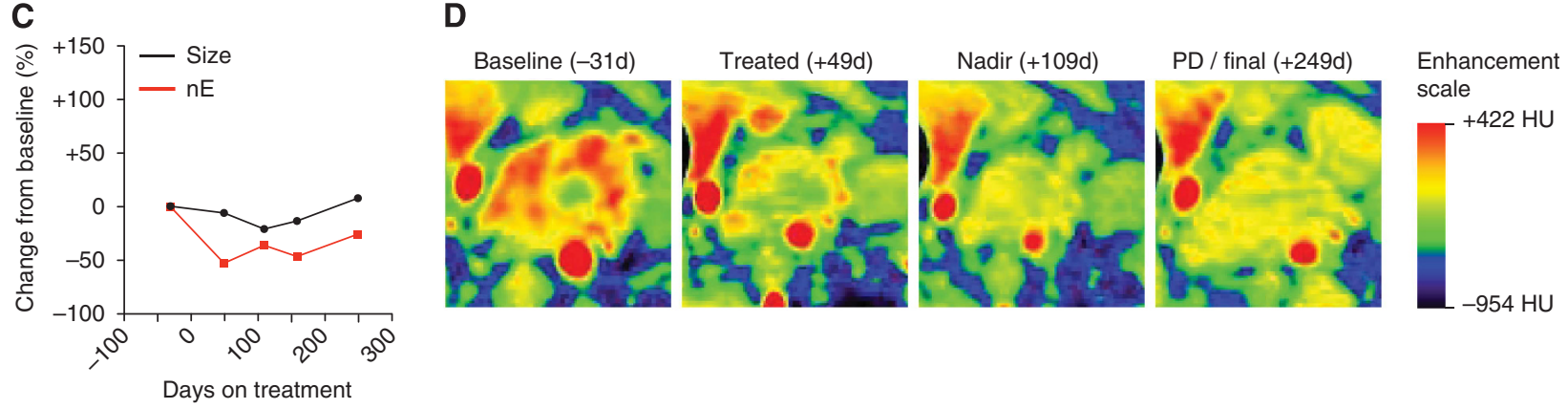

E

$\mathbf{F}$
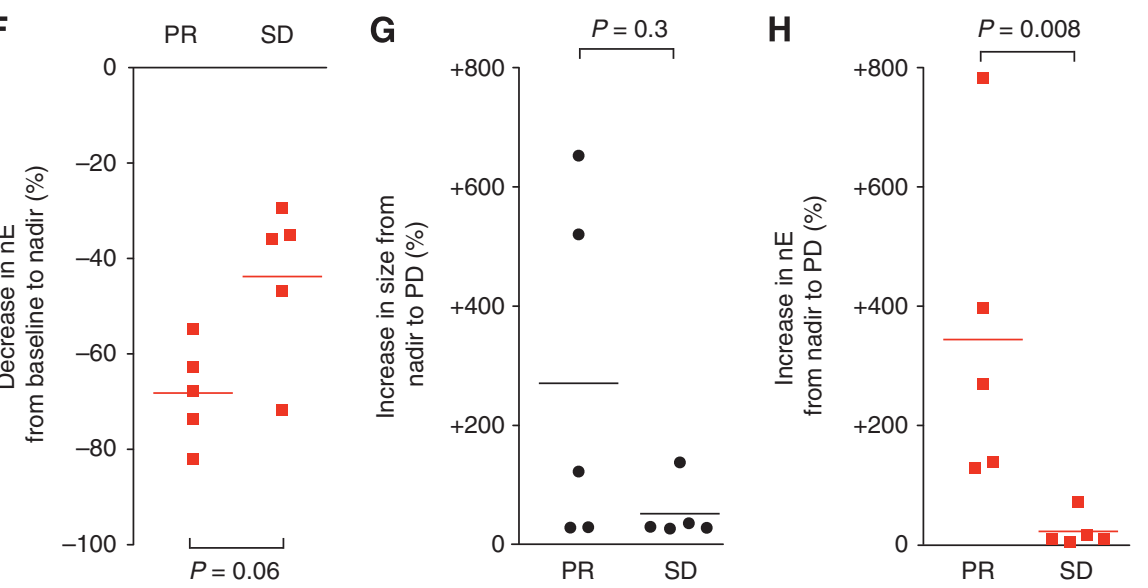

Figure 5. Longitudinal monitoring of lesions until progression. Where data were available, individual lesions were monitored longitudinally until they progressed. (A and B) Example of a lesion that underwent PR as the best response and then progressed (an 82-year-old man treated with pazopanib, hilar lymph node metastasis). ( $C$ and $\mathbf{D})$ Example of a lesion that underwent SD as the best response and then progressed (61-year-old woman treated with regorafenib, supraclavicular lymph node). Graphs in A and C show percentage change in size (black) or percentage change in $\mathrm{nE}$ (red), relative to baseline, quantified at all time points for which data were available. In B and D, pseudo-coloured arterial phase contrast-enhanced CT images of the baseline scan (baseline), first on-treatment scan (treated), scan at nadir (nadir), scan at progression $(P D)$ and/or the final available scan (final) are shown (number of days on treatment are indicated in parenthesis). (E) Percentage reductions in size from baseline to nadir in the lesions that underwent PR or SD as best response are compared $(P=0.01)$. (F) Percentage reductions in $\mathrm{nE}$ between the baseline and nadir in the lesions that underwent PR or SD as best response are compared $(P=0.06)$. (G) Percentage increases in size from nadir to progression in the lesions that underwent PR or SD as best response are compared $(P=0.3)$. (H) Percentage increases in $n E$ from nadir to progression in the lesions that underwent PR or SD as best response are compared $(P=0.008)$.

could be achieved with appropriate therapy. Interestingly, re-establishment of a vasculature was more pronounced in lesions that had PR as the best response, when compared with lesions that had SD as the best response (Figure 6E and F). We believe that this has not been previously reported. One interpretation of these data is that the biology of lesions that undergo PR as the best response may be different to that of lesions that undergo SD as the best response. These PR lesions may be intrinsically more dependent on a vascular supply for survival and therefore more dependent on re-vascularisation in order to progress. Alternatively, in lesions that undergo $\mathrm{PR}$ as the best response, there may be a stronger selective pressure for resistant tumour subclones that go on to drive TKIresistant tumour vascularisation. Importantly, if the biological mechanism mediating acquired resistance in PR lesions is different from that of SD lesions, then this may influence the type of therapeutic approach necessary to combat acquired resistance in these different scenarios. However, it should be noted that the number of lesions on which this observation is based is small $(n=10)$ and so this finding does require validation in a larger set of lesions.

Although the four TKIs utilised in this study target similar signalling pathways, the agents are administered on different schedules (see Table 2) and they differ subtly in their potency against individual receptors (see Table 3). Of interest, a trial designed to examine the comparative efficacies of scheduling sunitinib at $50 \mathrm{mg}$ daily for 28 days followed by 14 days off 
A

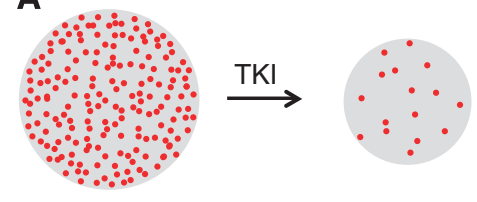

B

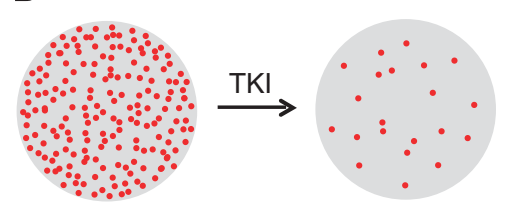

E

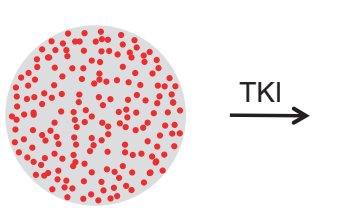

$\mathbf{F}$

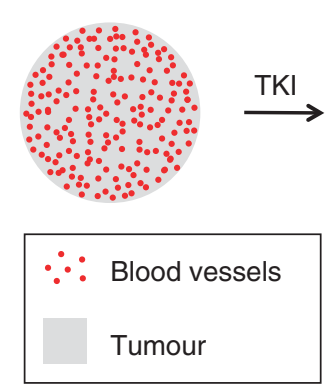

C

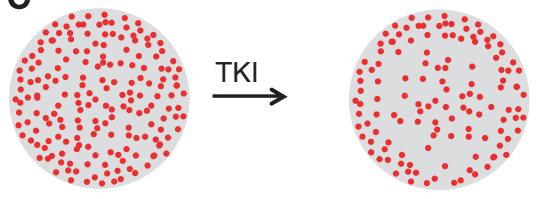

D
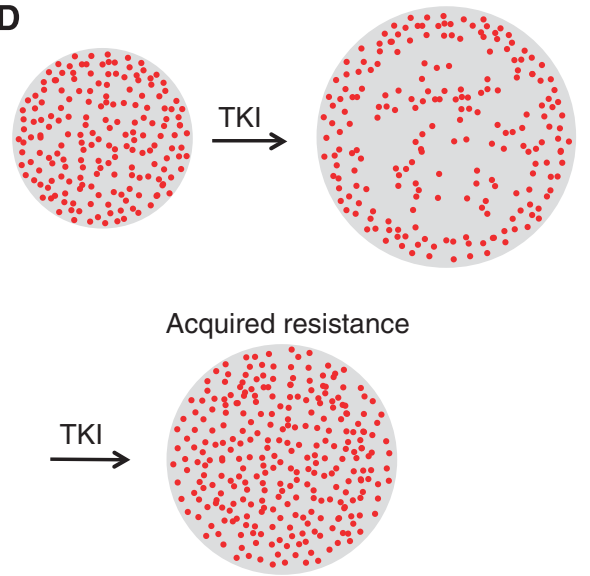

Acquired resistance

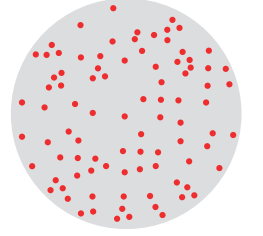

\section{.}

TKI

SD

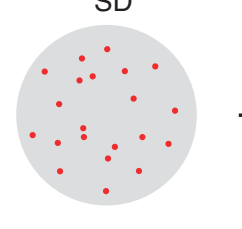

(n) 
Marsden NHS Foundation Trust, The Institute of Cancer Research and Mount Vernon Cancer Centre.

\section{REFERENCES}

Bergers G, Hanahan D (2008) Modes of resistance to anti-angiogenic therapy. Nat Rev Cancer 8(8): 592-603.

Bottsford-Miller JN, Coleman RL, Sood AK (2012) Resistance and escape from antiangiogenesis therapy: clinical implications and future strategies. J Clin Oncol 30(32): 4026-4034.

Busch J, Seidel C, Weikert S, Wolff I, Kempkensteffen C, Weinkauf L, Hinz S, Magheli A, Miller K, Grunwald V (2011) Intrinsic resistance to tyrosine kinase inhibitors is associated with poor clinical outcome in metastatic renal cell carcinoma. BMC Cancer 11: 295.

Casanovas O, Hicklin DJ, Bergers G, Hanahan D (2005) Drug resistance by evasion of antiangiogenic targeting of VEGF signaling in late-stage pancreatic islet tumors. Cancer Cell 8(4): 299-309.

Cowey CL, Fielding JR, Rathmell WK (2010a) The loss of radiographic enhancement in primary renal cell carcinoma tumors following multitargeted receptor tyrosine kinase therapy is an additional indicator of response. Urology 75(5): 1108-13 e1.

Cowey CL, Sonpavde G, Hutson TE (2010b) New advancements and developments in treatment of renal cell carcinoma: focus on pazopanib. Onco Targets Ther 3: 147-155.

Dome B, Hendrix MJ, Paku S, Tovari J, Timar J (2007) Alternative vascularization mechanisms in cancer: pathology and therapeutic implications. Am J Pathol 170(1): 1-15.

Ebos JM, Kerbel RS (2011) Antiangiogenic therapy: impact on invasion, disease progression, and metastasis. Nat Rev Clin Oncol 8(4): 210-221.

Ebos JM, Lee CR, Kerbel RS (2009) Tumor and host-mediated pathways of resistance and disease progression in response to antiangiogenic therapy. Clin Cancer Res 15(16): 5020-5025.

Eisenhauer EA, Therasse P, Bogaerts J, Schwartz LH, Sargent D, Ford R, Dancey J, Arbuck S, Gwyther S, Mooney M, Rubinstein L, Shankar L, Dodd L, Kaplan R, Lacombe D, Verweij J (2009) New response evaluation criteria in solid tumours: revised RECIST guideline (version 1.1). Eur J Cancer 45(2): 228-247.

Flaherty KT, Rosen MA, Heitjan DF, Gallagher ML, Schwartz B, Schnall MD, O'Dwyer PJ (2008) Pilot study of DCE-MRI to predict progression-free survival with sorafenib therapy in renal cell carcinoma. Cancer Biol Ther 7(4): 496-501.

Fournier LS, Oudard S, Thiam R, Trinquart L, Banu E, Medioni J, Balvay D, Chatellier G, Frija G, Cuenod CA (2010) Metastatic renal carcinoma: evaluation of antiangiogenic therapy with dynamic contrast-enhanced CT. Radiology 256(2): 511-518.

Gerlinger M, Rowan AJ, Horswell S, Larkin J, Endesfelder D, Gronroos E, Martinez P, Matthews N, Stewart A, Tarpey P, Varela I, Phillimore B, Begum S, McDonald NQ, Butler A, Jones D, Raine K, Latimer C, Santos CR, Nohadani M, Eklund AC, Spencer-Dene B, Clark G, Pickering L, Stamp G, Gore M, Szallasi Z, Downward J, Futreal PA, Swanton C (2012) Intratumor heterogeneity and branched evolution revealed by multiregion sequencing. N Engl J Med 366(10): 883-892.

Griffioen AW, Mans LA, de Graaf AM, Nowak-Sliwinska P, de Hoog CL, de Jong TA, Vyth-Dreese FA, van Beijnum JR, Bex A, Jonasch E (2012) Rapid angiogenesis onset after discontinuation of sunitinib treatment of renal cell carcinoma patients. Clin Cancer Res 18(14): 3961-3971.

Guo XL, Li D, Sun K, Wang J, Liu Y, Song JR, Zhao QD, Zhang SS, Deng WJ, Zhao X, Wu MC, Wei LX (2013) Inhibition of autophagy enhances anticancer effects of bevacizumab in hepatocarcinoma. J Mol Med 91(4): 473-483.

Hahn OM, Yang C, Medved M, Karczmar G, Kistner E, Karrison T, Manchen E, Mitchell M, Ratain MJ, Stadler WM (2008) Dynamic contrast-enhanced magnetic resonance imaging pharmacodynamic biomarker study of sorafenib in metastatic renal carcinoma. J Clin Oncol 26(28): 4572-4578.

Han KS, Jung DC, Choi HJ, Jeong MS, Cho KS, Joung JY, Seo HK, Lee KH, Chung J (2010) Pretreatment assessment of tumor enhancement on contrast-enhanced computed tomography as a potential predictor of treatment outcome in metastatic renal cell carcinoma patients receiving antiangiogenic therapy. Cancer 116(10): 2332-2342.

Heng DY, Mackenzie MJ, Vaishampayan UN, Bjarnason GA, Knox JJ, Tan MH, Wood L, Wang Y, Kollmannsberger C, North S, Donskov F,
Rini BI, Choueiri TK (2012) Primary anti-vascular endothelial growth factor (VEGF)-refractory metastatic renal cell carcinoma: clinical characteristics, risk factors, and subsequent therapy. Ann Oncol 23(6): $1549-1555$.

Holash J, Maisonpierre PC, Compton D, Boland P, Alexander CR, Zagzag D, Yancopoulos GD, Wiegand SJ (1999) Vessel cooption, regression, and growth in tumors mediated by angiopoietins and VEGF Science 284(5422): 1994-1998.

Hu YL, DeLay M, Jahangiri A, Molinaro AM, Rose SD, Carbonell WS, Aghi MK (2012a) Hypoxia-induced autophagy promotes tumor cell survival and adaptation to antiangiogenic treatment in glioblastoma. Cancer Res 72(7): 1773-1783.

Hu YL, Jahangiri A, Delay M, Aghi MK (2012b) Tumor cell autophagy as an adaptive response mediating resistance to treatments such as antiangiogenic therapy. Cancer Res 72(17): 4294-4299.

Huang D, Ding Y, Zhou M, Rini BI, Petillo D, Qian CN, Kahnoski R, Futreal PA, Furge KA, Teh BT (2010) Interleukin-8 mediates resistance to antiangiogenic agent sunitinib in renal cell carcinoma. Cancer Res 70(3): 1063-1071.

Jayson GC, Hicklin DJ, Ellis LM (2012) Antiangiogenic therapy-evolving view based on clinical trial results. Nat Rev Clin Oncol 9(5): 297-303.

Jinzaki M, Tanimoto A, Mukai M, Ikeda E, Kobayashi S, Yuasa Y, Narimatsu Y, Murai M (2000) Double-phase helical CT of small renal parenchymal neoplasms: correlation with pathologic findings and tumor angiogenesis. J Comput Assist Tomogr 24(6): 835-842.

Kopetz S, Hoff PM, Morris JS, Wolff RA, Eng C, Glover KY, Adinin R, Overman MJ, Valero V, Wen S, Lieu C, Yan S, Tran HT, Ellis LM, Abbruzzese JL, Heymach JV (2010) Phase II trial of infusional fluorouracil, irinotecan, and bevacizumab for metastatic colorectal cancer: efficacy and circulating angiogenic biomarkers associated with therapeutic resistance. J Clin Oncol 28(3): 453-459.

Krajewski KM, Guo M, Van den Abbeele AD, Yap J, Ramaiya N, Jagannathan J, Heng DY, Atkins MB, McDermott DF, Schutz FA, Pedrosa I, Choueiri TK (2011) Comparison of four early posttherapy imaging changes (EPTIC; RECIST 1.0, tumor shrinkage, computed tomography tumor density, Choi criteria) in assessing outcome to vascular endothelial growth factor-targeted therapy in patients with advanced renal cell carcinoma. Eur Urol 59(5): 856-862.

Kumar R, Knick VB, Rudolph SK, Johnson JH, Crosby RM, Crouthamel MC, Hopper TM, Miller CG, Harrington LE, Onori JA, Mullin RJ, Gilmer TM, Truesdale AT, Epperly AH, Boloor A, Stafford JA, Luttrell DK, Cheung M (2007) Pharmacokinetic-pharmacodynamic correlation from mouse to human with pazopanib, a multikinase angiogenesis inhibitor with potent antitumor and antiangiogenic activity. Mol Cancer Ther 6(7): 2012-2021.

Lassau N, Koscielny S, Albiges L, Chami L, Benatsou B, Chebil M, Roche A, Escudier BJ (2010) Metastatic renal cell carcinoma treated with sunitinib: early evaluation of treatment response using dynamic contrast-enhanced ultrasonography. Clin Cancer Res 16(4): 1216-1225.

Leenders WP, Kusters B, Verrijp K, Maass C, Wesseling P, Heerschap A, Ruiter D, Ryan A, de Waal R (2004) Antiangiogenic therapy of cerebral melanoma metastases results in sustained tumor progression via vessel co-option. Clin Cancer Res 10(18 Pt 1): 6222-6230.

Leite de Oliveira R, Hamm A, Mazzone M (2011) Growing tumor vessels: more than one way to skin a cat-implications for angiogenesis targeted cancer therapies. Mol Aspects Med 32(2): 71-87.

Mancuso MR, Davis R, Norberg SM, O’Brien S, Sennino B, Nakahara T, Yao VJ, Inai T, Brooks P, Freimark B, Shalinsky DR, Hu-Lowe DD, McDonald DM (2006) Rapid vascular regrowth in tumors after reversal of VEGF inhibition. J Clin Invest 116(10): 2610-2621.

McIntyre A, Patiar S, Wigfield S, Li JL, Ledaki I, Turley H, Leek R, Snell C, Gatter K, Sly WS, Vaughan-Jones RD, Swietach P, Harris AL (2012) Carbonic anhydrase IX promotes tumor growth and necrosis in vivo and inhibition enhances anti-VEGF therapy. Clin Cancer Res 18(11): 3100-3111.

Mendel DB, Laird AD, Xin X, Louie SG, Christensen JG, Li G, Schreck RE, Abrams TJ, Ngai TJ, Lee LB, Murray LJ, Carver J, Chan E, Moss KG, Haznedar JO, Sukbuntherng J, Blake RA, Sun L, Tang C, Miller T, Shirazian S, McMahon G, Cherrington JM (2003) In vivo antitumor activity of SU11248, a novel tyrosine kinase inhibitor targeting vascular endothelial growth factor and platelet-derived growth factor receptors: determination of a pharmacokinetic/pharmacodynamic relationship. Clin Cancer Res 9(1): 327-337. 
Motzer R, Hutson TE, Reeves J, Hawkins R, Guo J, Nathan P, Staehler M, De Souza P, Merchan JR, Fife K, Jin J, Jones R, Uemura H, De Giorgi U, Harmenberg U, Wang J, Cella D, McCann L, Deen K, Choueiri T (2012a) Randomized open-label phase III trial of pazopanib versus sunitinib in first-line treatment of patients with metastatic renal cell carcinoma (MRCC): Results of the COMPARZ trial. (ESMO Congress. Presented October 1, 2012, Vienna. Abstract LBA8.).

Motzer RJ, Hutson TE, Olsen MR, Hudes GR, Burke JM, Edenfield WJ, Wilding G, Agarwal N, Thompson JA, Cella D, Bello A, Korytowsky B, Yuan J, Valota O, Martell B, Hariharan S, Figlin RA (2012b) Randomized phase II trial of sunitinib on an intermittent versus continuous dosing schedule as first-line therapy for advanced renal cell carcinoma. J Clin Oncol 30(12): 1371-1377.

Motzer RJ, Hutson TE, Tomczak P, Michaelson MD, Bukowski RM, Oudard S, Negrier S, Szczylik C, Pili R, Bjarnason GA, Garcia-del-Muro X, Sosman JA, Solska E, Wilding G, Thompson JA, Kim ST, Chen I, Huang X, Figlin RA (2009) Overall survival and updated results for sunitinib compared with interferon alfa in patients with metastatic renal cell carcinoma. J Clin Oncol 27(22): 3584-3590.

Motzer RJ, Hutson TE, Tomczak P, Michaelson MD, Bukowski RM, Rixe O, Oudard S, Negrier S, Szczylik C, Kim ST, Chen I, Bycott PW, Baum CM, Figlin RA (2007) Sunitinib versus interferon alfa in metastatic renal-cell carcinoma. N Engl J Med 356(2): 115-124.

Nardo G, Favaro E, Curtarello M, Moserle L, Zulato E, Persano L, Rossi E, Esposito G, Crescenzi M, Casanovas O, Sattler U, Mueller-Klieser W, Biesalski B, Thews O, Canese R, Iorio E, Zanovello P, Amadori A, Indraccolo S (2011) Glycolytic phenotype and AMP kinase modify the pathologic response of tumor xenografts to VEGF neutralization. Cancer Res 71(12): 4214-4225.

Nathan PD, Vinayan A, Stott D, Juttla J, Goh V (2010) CT response assessment combining reduction in both size and arterial phase density correlates with time to progression in metastatic renal cancer patients treated with targeted therapies. Cancer Biol Ther 9(1): 15-19.

O'Connor JP, Jayson GC (2012) Do imaging biomarkers relate to outcome in patients treated with VEGF inhibitors? Clin Cancer Res 18(24): 6588-6598.

Pezzella F, Di Bacco A, Andreola S, Nicholson AG, Pastorino U, Harris AL (1996) Angiogenesis in primary lung cancer and lung secondaries. Eur J Cancer 32A(14): 2494-2500.

Porta C, Paglino C, Imarisio I, Ganini C, Sacchi L, Quaglini S, Giunta V, De Amici M (2012) Changes in circulating pro-angiogenic cytokines, other than VEGF, before progression to sunitinib therapy in advanced renal cell carcinoma patients. Oncology 84(2): 115-122.

Powles T, Sharpe K, Berney D, Kayani I, Doshi R, Stewart GD, Reynolds AR, Bex A, Sarwar N, Chowdhury S (2013) Dynamic molecular changes with VEGF targeted therapy in metastatic clear cell renal cancer. J Clin Oncol. 31 (suppl 6; abstract 437).

Rapisarda A, Melillo G (2012) Overcoming disappointing results with antiangiogenic therapy by targeting hypoxia. Nat Rev Clin Oncol 9(7): 378-390.

Rini BI, Atkins MB (2009) Resistance to targeted therapy in renal-cell carcinoma. Lancet Oncol 10(10): 992-1000.

Sardari Nia P, Hendriks J, Friedel G, Van Schil P, Van Marck E (2007) Distinct angiogenic and non-angiogenic growth patterns of lung metastases from renal cell carcinoma. Histopathology 51(3): 354-361.

Sennino B, McDonald DM (2012) Controlling escape from angiogenesis inhibitors. Nat Rev Cancer 12(10): 699-709.

Shojaei F, Lee JH, Simmons BH, Wong A, Esparza CO, Plumlee PA, Feng J, Stewart AE, Hu-Lowe DD, Christensen JG (2010) HGF/c-Met acts as an alternative angiogenic pathway in sunitinib-resistant tumors. Cancer Res 70(24): 10090-10100.

Sitohy B, Nagy JA, Dvorak HF (2012) Anti-VEGF/VEGFR therapy for cancer: reassessing the target. Cancer Res 72(8): 1909-1914.

Sitohy B, Nagy JA, Jaminet SC, Dvorak HF (2011) Tumor-surrogate blood vessel subtypes exhibit differential susceptibility to anti-VEGF therapy. Cancer Res 71(22): 7021-7028.
Smith AD, Lieber ML, Shah SN (2010a) Assessing tumor response and detecting recurrence in metastatic renal cell carcinoma on targeted therapy: importance of size and attenuation on contrast-enhanced CT. AJR Am J Roentgenol 194(1): 157-165.

Smith AD, Shah SN, Rini BI, Lieber ML, Remer EM (2010b) Morphology, Attenuation, Size, and Structure (MASS) criteria: assessing response and predicting clinical outcome in metastatic renal cell carcinoma on antiangiogenic targeted therapy. AJR Am J Roentgenol 194(6): 1470-1478.

Sternberg CN, Davis ID, Mardiak J, Szczylik C, Lee E, Wagstaff J, Barrios CH, Salman P, Gladkov OA, Kavina A, Zarba JJ, Chen M, McCann L, Pandite L, Roychowdhury DF, Hawkins RE (2010) Pazopanib in locally advanced or metastatic renal cell carcinoma: results of a randomized phase III trial. J Clin Oncol 28(6): 1061-1068.

van der Veldt AA, Meijerink MR, van den Eertwegh AJ, Haanen JB, Boven E (2010) Choi response criteria for early prediction of clinical outcome in patients with metastatic renal cell cancer treated with sunitinib. $\mathrm{Br} \mathrm{J}$ Cancer 102(5): 803-809.

Vermeulen PB, Colpaert C, Salgado R, Royers R, Hellemans H, Van Den Heuvel E, Goovaerts G, Dirix LY, Van Marck E (2001) Liver metastases from colorectal adenocarcinomas grow in three patterns with different angiogenesis and desmoplasia. J Pathol 195(3): 336-342.

Wang JH, Min PQ, Wang PJ, Cheng WX, Zhang XH, Wang Y, Zhao XH, Mao XQ (2006) Dynamic CT evaluation of tumor vascularity in renal cell carcinoma. AJR Am J Roentgenol 186(5): 1423-1430.

Wedge SR, Kendrew J, Hennequin LF, Valentine PJ, Barry ST, Brave SR, Smith NR, James NH, Dukes M, Curwen JO, Chester R, Jackson JA, Boffey SJ, Kilburn LL, Barnett S, Richmond GH, Wadsworth PF, Walker M, Bigley AL, Taylor ST, Cooper L, Beck S, Jurgensmeier JM, Ogilvie DJ (2005) AZD2171: a highly potent, orally bioavailable, vascular endothelial growth factor receptor-2 tyrosine kinase inhibitor for the treatment of cancer. Cancer Res 65(10): 4389-4400.

Welti JC, Gourlaouen M, Powles T, Kudahetti SC, Wilson P, Berney DM, Reynolds AR (2011) Fibroblast growth factor 2 regulates endothelial cell sensitivity to sunitinib. Oncogene 30(10): 1183-1193.

Welti JC, Powles T, Foo S, Gourlaouen M, Preece N, Foster J, Frentzas S, Bird D, Sharpe K, van Weverwijk A, Robertson D, Soffe J, Erler JT, Pili R, Springer CJ, Mather SJ, Reynolds AR (2012) Contrasting effects of sunitinib within in vivo models of metastasis. Angiogenesis 15(4): 623-641.

Wilhelm SM, Dumas J, Adnane L, Lynch M, Carter CA, Schutz G, Thierauch KH, Zopf D (2011) Regorafenib (BAY 73-4506): a new oral multikinase inhibitor of angiogenic, stromal and oncogenic receptor tyrosine kinases with potent preclinical antitumor activity. Int $J$ Cancer 129(1): 245-255.

Xu J, Wang J, Xu B, Ge H, Zhou X, Fang JY (2013) Colorectal cancer cells refractory to anti-VEGF treatment are vulnerable to glycolytic blockade due to persistent impairment of mitochondria. Mol Cancer Ther 12(5): 717-724.

Yu JL, Rak JW, Carmeliet P, Nagy A, Kerbel RS, Coomber BL (2001) Heterogeneous vascular dependence of tumor cell populations. Am J Pathol 158(4): 1325-1334.

Yu JL, Rak JW, Coomber BL, Hicklin DJ, Kerbel RS (2002) Effect of p53 status on tumor response to antiangiogenic therapy. Science 295(5559): $1526-1528$.

Zulato E, Curtarello M, Nardo G, Indraccolo S (2012) Metabolic effects of anti-angiogenic therapy in tumors. Biochimie 94(4): 925-931.

This work is published under the standard license to publish agreement. After 12 months the work will become freely available and the license terms will switch to a Creative Commons AttributionNonCommercial-Share Alike 3.0 Unported License.

Supplementary Information accompanies this paper on British Journal of Cancer website (http://www.nature.com/bjc) 